\title{
KEPUASAN KERJA GURU DITINJAU DARI KEPEMIMPINAN TRANSFORMASIONAL KEPALA MADRASAH DAN BUDAYA ORGANISASI
}

\author{
Muhammad Sulaeman ${ }^{1}$, M. Entang ${ }^{2}$, Hari Muharam ${ }^{2}$ \\ ${ }^{1}$ Guru MA At-Tahsiniyyah, Sukabumi, Jawa Barat \\ ${ }^{2}$ Program Pascasarjana Universitas Pakuan, \\ Email: pasca@unpak.ac.id
}

\begin{abstract}
The objective of this research is to outline the correlation of principal transformational leadhership and organization culture with teacher work job satisfaction. This research was conducted in Islamic junior school Kadudampit district by applying survey analysis method and the data were collected from the given quessionnaires. 153 of population and 111 of samples were taken by using proportional random sampling. The research findings reveals that: 1) there is a principal's positive correlation between transformational ledhership with teacher job satisfacttion, 2) there is principal's positive correlation between organization culture with teacher job satisfaction., 3) there is principal's positive correlation between transformational leadhership and organization culture with teacher work job satisfaction. The findings of this research shows that teacher job satisfaction can be achieved through improvement of transformational ledhership and organization culture.
\end{abstract}

Keywords : Transformational leadership, Organizational Culture, teacher Job Satisfaction.

\begin{abstract}
ABSTRAK
Penelitian ini bertujuan untuk menemukan Hubungan antara Kepemimpinan Transformasional Kepala Madrasah dan Budaya Organisasi dengan Kepuasan Kerja Guru. Penelitian dilaksanakan di Madrasah Ibtidaiyah Se KKMI Kadudampit Tahun 2017, dengan menggunakan metode penelitian survey dan alat ukur instrumen kuisioner. Populasi dalam penelitian adalah 153 dan jumlah sampel sebanyak 111 yang diambil secara proposional random sampling. Penelitian ini menemukan : (1) terdapat hubungan yang positif dan signifikan antara kepemimpinan transformasional kepala madrasah dengan kepuasan kerja guru (2) terdapat hubungan yang positif dan signifikan antara budaya organisasi dengan kepuasan kerja guru kerja guru. (3) terdapat hubungan yang positif dan signifikan antara kepemimpinan transformasional kepala madrasah dan budaya organisasi secara bersamasama dengan kepuasan kerja guru. Hal ini berarti bahwa untuk peningkatan kepuasan kerja guru madrasah dapat ditingkatkan melalui kepemimpinan transformasional kepala madrasah dan budaya organisasi.
\end{abstract}

Kata Kunci : kepemimpinan transformasional, budaya organisasi, dan kepuasan kerja

\section{PENDAHULUAN}

Pendidikan merupakan kebutuhan yang sangat penting bagi berlangsungnya kehidupan manusia karena situasi kehidupan dewasa ini sangat komplek seiring pergeseran pola kehidupan yang sangat menuntut pengembangan potensi diri setiap orang. Pengembangan potensi diri tersebut, pada dasarnya merupakan suatu upaya mengaktualisasikan dan 
mengekspresikan kapabilitas manusia dalam menjalani kehidupannya di masyarakat. Perubahan dari hal tersebut bermakna bahwa pentingnya tingkat pendidikan menuntut pada upaya untuk menyelenggarakan pendidikan secara baik, tertata dan sistematis serta antisipatif terhadap implikasi yang terjadi tanpa membedakan latar belakang penyelenggara pendidikan itu sendiri baik sekolah di bawah kemendikbud atau di bawah naungan kementerian agama. sehingga proses yang terjadi di dalamnya dapat menjadi suatu sumbangan besar bagi peningkatan kualitas sumber daya manusia untuk mengembangkan potensinya, yang pada akhirnya akan berdampak pada makin meningkatnya kualitas kehidupan masyarakat.

Sekolah sebagai lembaga formal merupakan salah satu organisasi yang ikut bertanggung jawab terhadap upaya mencerdaskan kehidupan bangsa dan ikut mempersiapkan peserta didik menjadi orang yang bertaqwa dan berakhlak mulia. Sebagai lembaga yang mencetak generasi bangsa yang cerdas, melibatkan komponen-komponen yang ada, seperti guru, tata usaha, dan kepala sekolah.

Berdasarkan latar belakang di atas penelitian ini akan menjelaskan bagaimana upaya meningkatkan kepuasan kerja dengan mengkaji bubungan antara kepemimpinan transformasional dan budaya organisasi terhadap budaya kerja.

\section{Kepuasan Kerja}

Untuk lebih memahami keberartian, kepuasan kerja bagi suatu lembaga terlebih dahulu peneliti akan mengutip beberapa pengertian kepuasan kerja menurut pakar ahli seperti yang dikemukakan oleh Davis (dalam Mangkunegara,2013:117) mengemukakan bahwa kepuasan kerja adalah perasaan menyokong atau tidak menyokong yang dialami pegawai dalam bekerja. Handoko (2001:193) memberikan definisi kepuasan kerja (job satisfaction) adalah keadaan emosional yang menyenangkan atau tidak menyenangkan dengan cara para karyawan memandang pekerjaan mereka. Gibson, (2003:449) menyatakan, "job satisfaction is refers to the positive or negative aspectof an individual's attitude his job or some feature of the job" (Artinya, kepuasan kerja cenderung mendukung aspek positif atau negatif dari reaksi invidu menuju tugasnya di masa depan).

Kepuasan Kerja adalah tingkat perasaan positif atau negatif individu tentang sebuah pekerjaan, sesuai dengan pendapat Schemerhorn, (2010:72-73).Hariandja (2009:290-291) memberikan definisi kepuasan kerja adalah sejauh mana individu merasakan secara positif atau negatif berbagai macam faktor atau dimensi dari tugas-tugas dalam pekerjaannya. Kepuasan kerja adalah perasaan yang dialami guru dalam berbagai aspek pekerjaannya (Patras 2017). Kepuasan kerja guru merupakan respon emosional yang dirasakan guru setelah melakukan penilian terhadap pekerjaannya sebagai guru (Hidayat 2017)

Berdasarkan hasil analisis dan kajian teori dapat disintesiskan bahwa yang dimaksud kepuasan kerja adalah perasaan menyenangkan atau tidaknya yang dialami seseorang dalam memandang sesuatu pekerjaan baik dari penilaian maupun pengalaman kerja karena yang dihasilkan antara harapan dan kenyataan kadang tidak sesuai.

\section{Kepemimpinan Transformasional}

Gibson (2012:410) pemimpin yang secara tidak langsung orang yang dapat mempengaruhi dan hubungan antar perseorangan yang meliputi kepemimpinanya. Sedangkan menurut Stephen P Robbins dan Timoty A Judge leadership as ability to influence a group toward the achievement of a vision or set of goal. Colquitt (2009.488) mengemukakan bahwa kepemimpinan transformasional dipandang lebih sebagai pola pendekatan pemberi motivasi daripada pendekatan manajerial.

Luthans (2011: 430) mendefinisikan bahwa kepemimpinan transformasional adalah tipe kepemimpinan yang berdasar pada nilai, kepercayaan dan kebutuhan bawahannya. Kepemimpinan transformasional adalah bentuk kepemimpinan yang esensinya merubah 
potensi menjadi nyata. Sebagaimana yang diungkapkan Leithwood (dalam Masaong.2011:166) menyatakan bahwa kepemimpinan transformasional menggiring SDM yang dipimpin kearah yang tumbuhnya sensitivitas pembinaan dan pengembangan organisasi,pengembangan visi secara bersama,pendistribusian kewenangan kepemimpinan,dan pembangunan kultur organisasi sekolah yang menjadi keharusan dalam skema restrukturisasi sekolah.

Berdasarkan beberapa teori di atas dapat disintesiskan kepemimpinan transformasional adalah kepemimpinan yang memiliki wawasan serta berupaya memperbaiki, mengembangkan organisasi, dapat mempengaruhi dan menginspirasi orang lain untuk melakukan aktivitas yang dikehendaki dalam rangka mencapai tujuan bersama dalam organisasi madrasah.

\section{Budaya Organisasi}

Hamby (dalam Sanusi, 2009:1) mendefinisikan budaya sebagai sesuatu yang dilakukan,dipikirkan,dan diciptakan oleh manusia didalam masyarakat serta termasuk juga akumulasi sejarah dari obyek-obyek atau perbuatan yang dilakukan sepanjang waktu. Yukl (2009:132) berpendapat bahwa istilah budaya organisasi digunakan untuk menjelaskan nilainilai bersama dan kepercayaan para anggota mengenai aktivitas oraganisasi dan hubungan antar pribadi. Budaya organisasi disebut juga kultur organisasi, dengan meminjam istilah asing culture (bahasa Inggris).

Secara umum Schein ( 2004:17) dari MIT dalam tulisannya tentang Organizational Culture \& Leadership mendefinisikan budaya sebagai: "A pattern of shared basic assumptions that the group learned as it solved its problems of external adaptation and internal integration, that has worked well enough to be considered valid and, therefore, to be taught to new members as the correct way you perceive, think, and feel in relation to those problems".Gibson (2012:31) mendefinisikan budaya organisasi adalah sebuah persepektif untuk saling mengerti tingkah laku individu-individu dan grup dalam organisasi yang masing-masing mempunyai batasan-batasan. Sutrisno (2010:2) Budaya Organisasi dapat didefinisikan sebagai perangkat system nilai-nilai (values), keyakinan-keyakinan (beliefs),asumsi-asumsi (assumptions), atau norma-norma yang telah lama berlaku, disepakati dan diikuti oleh para anggota suatu organisasi sebagai pedoman perilaku dan pemecahan masalah-masalah organisasinya.

Berdasarkan uraian teori di atas dapat disintesiskan bahwa budaya organisasi adalah sesuatu yang dilakukan dan menjadi kebiasaan dalam organisasi, keyakinan dan kepercayaan bersama, norma-norma, nilai-nilai dan perilaku-perilaku yang dianut oleh seluruh anggota sekolah dalam rangka mencapai tujuan bersama.

\section{METODE PENELITIAN}

Penelitian ini adalah penelitian kuantitatif dengan pendekatan korelasional yang terdiri atas dua variabel bebas, yaitu kepemimpinan transformasional kepala sekolah $\left(\mathrm{X}_{1}\right)$ dan Budaya organissi $\left(\mathrm{X}_{2}\right)$, serta satu variabel terikat yaitu kepuasan kerja guru (Y).

Penelitian ini dilaksanakan di Madrasah Ibtidaiyah (MI) Swasta yang berada di Kecamatan Kadudampit Kabupaten Sukabumi. Tahapan penelitian dilaksanakan mulai bulan April 2017 sampai bulan Juli 2017 dengan rincian kegiatan melalui tahap perencanaan, pelaksanaan dan penyelesaian. Jumlah populasi pada penelitian adalah 153 orang guru. Dengan jumlah sampel 111 orang. 


\section{HASIL PENELITIAN}

\section{Pengujian Persyaratan Analisis}

1. Uji Normalitas

a. Uji normalitas pada Galat Baku Data Kepuasan Kerja Guru (Y) atas Kepemimpinan Transformasional Kepala Madrasah $\left(\mathbf{X}_{1}\right)$

Hasil perhitungan uji normalitas galat baku taksiran $\left(\mathrm{Y}-\hat{\mathrm{Y}}_{1}\right)$ variabel Kepuasan Kerja Guru (Y) atas Kepemimpinan Transformasional $\left(\mathrm{X}_{1}\right)$ diperoleh nilai $\mathrm{L}_{\text {hitung }}=0,078$ sedangkan nilai $\mathrm{L}_{\text {tabel }}=0,829$, persyaratan normal adalah $\mathrm{L}_{\mathrm{h}}<\mathrm{L}_{\mathrm{t}}$, dengan demikian galat baku taksiran $\left(\mathrm{Y}-\hat{\mathrm{Y}}_{1}\right)$ variabel Kepuasan Kerja Guru $(\mathrm{Y})$ atas Kepemimpinan Transformasional $\left(\mathrm{X}_{1}\right)$ berasal dari populasi yang berdistribusi normal.

\section{b. Uji normalitas Galat Baku Data Kepuasan Kerja Guru (Y) atas Budaya Organisasi $\left(\mathbf{X}_{2}\right)$}

Hasil perhitungan uji normalitas galat baku taksiran $\left(\mathrm{Y}-\hat{\mathrm{Y}}_{2}\right)$ variabel Kepuasan kerja guru (Y) atas Budaya Organisasi diperoleh nilai $\mathrm{L}_{\text {hitung }}=0,092$, sedangkan nilai $\mathrm{L}_{\text {tabel }}=0,539$, persyaratan normal adalah $\mathrm{L}_{\mathrm{h}}<\mathrm{L}_{\mathrm{t}}$, dengan demikian galat baku taksiran $\left(\mathrm{Y}-\hat{\mathrm{Y}}_{2}\right)$ variabel Kepuasan kerja guru (Y) atas Budaya Organisasi $\left(\mathrm{X}_{2}\right)$ berasal dari populasi yang berdistribusi normal.

\section{Uji Homogenitas}

\section{a. Uji Homogenitas Kepuasan Kerja Guru (Y) atas Kepemimpinan Transformasional $\left(\mathbf{X}_{1}\right)$}

Pengujian homogenitas dilakukan dengan menggunakan uji Bartlett. Berdasarkan hasil pengujian dipeoleh $\chi^{2}$ hitung $=90,30$, sedangkan $\chi^{2}$ tabel $=157,20$. Persyaratan data tersebut homogen bila $\chi^{2}{ }_{\text {hitung }}<\chi^{2}$ tabel. Hal tersebut bermakna bahwa kelompok data Kepuasan kerja guru (Y) atas Kepemimpinan Transformasional kepala madrasah $\left(\mathrm{X}_{1}\right)$ berasal dari populasi yang homogen.

\section{b. Uji Homogenitas Kepuasan kerja guru (Y) atas Budaya Organisasi $\left(\mathrm{X}_{2}\right)$}

Sebagaimana pengujian homogenitas varians data sebelumnya, pengujian homogenitas dilakukan dengan uji Bartlett. Berdasarkan hasil pengujian diperoleh nila $\chi^{2}$ hitung $=50,07$, sedangkan $\chi^{2}{ }_{\text {tabel }}=187,85$. Persyaratan data tersebut homogen bila $\chi^{2}$ hitung $<\chi{ }^{2}$ tabel. Hal tersebut bermakna bahwa kelompok data Kepuasan kerja guru (Y) atas Budaya Organisasi $\left(\mathrm{X}_{2}\right)$ berasal dari populasi yang homogen

\section{Pengujian Hipotesis}

1. Hubungan antara Kepemimpinan Transformasional Kepala Madrasah $\left(X_{1}\right)$ dengan Kepuasan Kerja Guru (Y)

Hasil uji keberartian persamaan regresi diperoleh Fhitung sebesar 16,21 sedangkan Ftabel sebesar 4,12 (dk pembilang $=1$, dk penyebut $=111$ dan $\alpha=0,05$ ) yang berarti nilai (Fhitung> Ftabel). Persamaan regresi tersebut linier atau tidak, perlu dilakukan uji linieritas yaitu dengan uji F. Perhitungan analisis sederhana menghasilkan koefisien korelasi $r_{\mathrm{y} 1}$ sebesar 0,5560, sedangkan koefisien determinan $r_{\text {y1 }}^{2}$ sebesar 0,4832 yang berarti faktor Kepemimpinan Transformasional kepala madrasah menunjukan hubungan antar variabel yang kuat dan memberikan kontribusi 48,32\% dengan Kepuasan sedangkan 55,60\% dipengaruhi oleh faktor lain.

Hasil perhitungan tabel 16 , diperoleh nilai $r_{\text {hitung }}(8,38)>r_{\text {tabel }}(1,62)$ dan $t_{\text {hitung }}=$ $8,38>\mathrm{t}_{\text {tabel }}=1,62$, karena koefisien korelasi antara variabel Kepemimpinan Transformasional kepala madrasah $\left(\mathrm{X}_{1}\right)$ dengan Kepuasan kerja guru $(\mathrm{Y})$ lebih besar dari koefisien korelasi pada tabel product moment, maka hipotesis yang menyatakan bahwa terdapat hubungan 
positif antara Kepemimpinan Transformasional kepala madrasah $\left(\mathrm{X}_{1}\right)$ dengan Kepuasan kerja guru(Y) dapat diterima, artinya makin tinggi Kepemimpinan Transformasional kepala madrasah maka makin tinggi dan baik pula Kepuasan kerja guru.

\section{Hubungan Variabel Budaya Organisasi $\left(\mathbf{X}_{2}\right)$ dengan Kepuasan Kerja Guru (Y)}

Hipotesis kedua yang diajukan dalam penelitian ini adalah terdapat hubungan positif antara Budaya Organisasi $\left(\mathrm{X}_{2}\right)$ dengan Kepuasan kerja guru (Y). Analisis linier sederhana antara Budaya Organisasidengan Kepuasan kerja guru memiliki persamaan regresi $\hat{\mathrm{Y}}=$ $0,009+0,06860 \mathrm{X}_{2}$ dengan arah koefisien regresi sebesar 0,06860 dan konstanta sebesar 0,009. Berdasarkan hasil uji keberartian persamaan regresi diperoleh $F_{\text {hitung }}$ sebesar 14,5 sedangkan $\mathrm{F}_{\text {tabel }}$ sebesar 3,8 (dk pembilang $=1$, dk penyebut $=111$ dan $\left.\alpha=0,05\right)$ yang berarti nilai $\left(\mathrm{F}_{\text {hitung }}>\mathrm{F}_{\text {tabel }}\right)$.

Hasil perhitungan tabel 18 , diperoleh nilai $r_{\text {hitung }}(13)>r_{\text {tabel }}(1,68)$ dan $t_{\text {hitung }}=13>t_{\text {tabel }}=$ 1,68 karena koefisien korelasi antara variable Budaya Organisasi $\left(\mathrm{X}_{2}\right)$ dengan Kepuasan kerja guru (Y) lebih besar dari koefisien korelasi pada table product moment, maka hipotesis yang menyatakan bahwa terdapat hubungan positif antara Budaya Organisasi $\left(\mathrm{X}_{2}\right)$ dengan Kepuasan kerja guru (Y) dapat diterima, artinya makin tinggi Budaya Organisasi maka makin tinggi Kepuasan kerja guru.

\section{Hubungan antara Variabel Kepemimpinan Transformasional Kepala Madrasah (X1) dan Budaya Organisasi (X2) dengan Kepuasan Kerja Guru (Y).}

\section{a. Uji Regresi Ganda}

Berdasarkan hasil uji keberartian persamaan regresi linier ganda diperoleh Fhitung sebesar 3645,012 sedangkan $F_{\text {tabel }}$ sebesar 3,46 (dk pembilang $=2 \mathrm{dk}$ penyebut $=111 \mathrm{dan} \alpha=$ $0,05)$ yang berarti nilai $\left(\mathrm{F}_{\text {hitung }}>\mathrm{F}_{\text {tabel }}\right)$.

Hasil menunjukkan nilai $\mathrm{F}=986,674(\mathrm{P}<0,01)$, maka persamaan regresi $\hat{\mathrm{Y}}=8,26+$ $0,38 \mathrm{X}_{1}+0,63 \mathrm{X}_{2}$. dinyatakan signifikan. Jadi $(\mathrm{P}<0,01)$ adalah signifikasi untuk persamaan regresi $\hat{Y}=8,26+0,38 X_{1}+0,63 X_{2}$. Kesimpulannya bahwa kepemimpinan transformasional dan budaya organisasi dapat digunakan untuk memprediksi produktivitas kerja guru.

\section{b. Uji Korelasi Ganda}

Nilai koefisien determinan $r_{\text {y1.2 }}^{2}$ sebesar 0,2422 yang berarti faktor Kepemimpinan Transformasional kepala madrasah $\left(\mathrm{X}_{1}\right)$ dan Budaya Organisasi $\left(\mathrm{X}_{2}\right)$ secara bersama-sama berperan memberikan kontribusi sebesar $24,22 \%$ terhadap Kepuasan kerja guru (Y). Hal ini berarti bahwa koefisien korelasi antara Kepemimpinan Transformasional kepala madrasah $\left(\mathrm{X}_{1}\right)$ dan Budaya Organisasi $\left(\mathrm{X}_{2}\right)$ secara bersama-sama dengan Kepuasan kerja guru (Y) adalah sangat signifikan.

\section{Uji Korelasi Parsial}

Hasil perhitungan korelasi antara $\left(\mathrm{X}_{1}\right)$ dengan $(\mathrm{Y})$ sebesar $\mathrm{r}_{\mathrm{y} 1.2}=0,4921$ dan $\mathrm{t}_{\text {hitung }}=$ 29863,430. Diketahui $t_{\text {tabel }}=3,46$ sedangkan syarat signifikan $t_{\text {hitung }}>t_{\text {tabel }}$. Hal ini berarti hubungan antara variabel Kepemimpinan Transformasional kepala madrasah $\left(\mathrm{X}_{1}\right)$ dengan variabel Kepuasan kerja guru (Y) adalah tetap signifikan apabila dikontrol oleh variable Budaya Organisasiatau dengan kata lain varibel Budaya Organisasi $\left(\mathrm{X}_{2}\right)$ tidak mempengaruhi hubungan antara variabel Kepemimpinan Transformasional kepala madrasah $\left(\mathrm{X}_{1}\right)$ dengan variabel Kepuasan kerja guru (Y).

Selanjutnya berdasarkan hasil perhitungan korelasi parsial dengan pengendali variabel Kepemimpinan Transformasional kepala madrasah $\left(X_{1}\right)$ diperoleh $r_{\mathrm{y} 2.1}=0,4921$ dan $t_{\text {hitung }}=$ 
29863,430 diketahui $t_{\text {tabel }}=3,46$ sedangkan syarat signifikan adalah $t_{\text {hitung }}>t_{\text {tabel }}$. Hal ini berari hubungan antara variabel Budaya Organisasidengan variabel Kepuasan kerja guru adalah tetap signifikan apabila dikontrol oleh variabel Kepemimpinan Transformasional kepala madrasah atau dengan kata lain variabel Kepemimpinan Transformasional kepala madrasah $\left(\mathrm{X}_{1}\right)$ tidak mempengaruhi hubungan antara variabel Budaya Organisasi $\left(\mathrm{X}_{2}\right)$ dengan variabel Kepuasan kerja guru (Y).

\section{PEMBAHASAN}

\section{Hubungan Antara Kepemimpinan Transformasional Kepala Madrasah $\left(\mathbf{X}_{1}\right)$ dengan Kepuasan Kerja Guru (Y)}

Secara teroritik kepemimpinan transformasional kepala madrasah adalah kepemimpinan yang memiliki wawasan dan berupaya memperbaiki dan mengembangkan organisasi dan dapat mempengaruhi dan menginspirasi orang lain untuk melakukan aktivitas yang dikehendaki dalam rangka mencapai tujuan bersama dalam organisasi madrasah, dengan indikator sebagai berikut: 1) kharismatik, 2) memberi teladan, 3) menginspirasi pengikut, 4) membangun komitmen untuk visi dan misi organisasi.

Dalam penelitian ini Hubungan antara Kepemimpinan Transformasional kepala madrasah (variabel $\mathrm{X}_{1}$ ) dengan Kepuasan kerja guru (variabel $\mathrm{Y}$ ) dapat ditunjukan dengan persamaan regresi $\hat{\mathrm{Y}}=135,363+0.0604 \mathrm{X}_{1}$. Persamaan ini memberikan arti nilai variabel dependen Kepuasan kerja guru (Y) dipengaruhi oleh variabel independen yaitu Kepemimpinan Transformasional kepala madrasah $\left(\mathrm{X}_{1}\right)$.

Nilai koefisien korelasi Kepemimpinan Transformasional kepala madrasah dengan Kepuasan kerja guru adalah $r_{\mathrm{y} 1}=0,5660$ dan koefisien determinasi $r_{\mathrm{y} 1}^{2}=0,4832$ yang dihasilkan, menunjukan tingkat hubungan yang sangat signifikan serta kontribusi yang diberikan oleh variabel Kepemimpinan Transformasional kepala madrasah adalah 56,60\% dengan Kepuasan kerja guru sedangkan $44,40 \%$ dipengaruhi oleh faktor lain diluar variabel yang diteliti.

Berdasarkan secara teoritik dan didukung oleh penelitian yang relevan, terdiri atas hubungan Kepemimpinan Transformasional kepala madrasah dengan Kepuasan kerja guru memiliki koefisien korelasi Kepemimpinan Transformasional kepala madrasah sebesar $r_{\mathrm{y} 1}=$ 0,5660 dan menurut penelitian yang relevan memiliki koefisien korelasi Kepemimpinan Transformasional kepala madrasah sebesar $\mathrm{r}=0,5660, \mathrm{P}<0.01$, maka dapat disimpulkan bahwa hubungan antara Kepemimpinan Transformasional kepala madrasah dengan Kepuasan kerja guru penelitian yang di teliti lebih besar dari penelitian yang relevan, maka dengan demikian penelitian ini tergolong sangat baik.

Berdasarkan Penelitian I Gede Anggi Wira Kesuma dan I Wayan Gede Supartha "pengaruh kepemimpinan transformasional terhadap Komitmen rganisasional dengan mediasi organizational Citizenship behavior dan kepuasan kerja" (2016: 3667-3705) memberikan kesimpulan bahwa terdapat hubungan positif yang signifikan ( $\mathrm{r}=0,365 \mathrm{p}<$ 0,05 ) antara kepemimpinan transformasional kepala madrasah dan kepuasan kerja guru. Semakin tinggi tingkat kepemimpinan transformasional kepala madrasah diprediksi akan semakin tinggi taraf kepuasan kerja guru.

\section{Hubungan antara Budaya Organisasi $\left(\mathrm{X}_{2}\right)$ dengan Kepuasan Kerja Guru (Y)}

Secara teoritik Budaya Organisasi sesuatu yang dilakukan dan menjadi kebiasaan dalam organisasi, keyakinan dan kepercayaan bersama, norma-norma, nilai-nilai dan perilaku-perilaku yang dianut oleh seluruh anggota sekolah dalam rangka mencapai tujuan bersama. Indikator budaya organisasi sekolah dalam penelitian ini meliputi; (1) norma yang 
ditanamkan di sekolah, (2) kesamaan visi tujuan sekolah, (3) kondisi lingkungan sekolah, (4) nilai dan perilaku warga sekolah, dan (5) keyakinan bersama.

Dalam penelitian ini hubungan antara Budaya Organisasi(variabel $\mathrm{X}_{2}$ ) dengan Kepuasan kerja guru (variabel Y) dapat ditunjukkan dengan persamaan regresi $\hat{\mathrm{Y}}=0,009+$ $0,06860 \mathrm{X}_{2}$. Persamaan ini memberikan arti nilai variabel dependen Kepuasan kerja guru(Y) dipengaruhi oleh variabel independen yaitu Budaya Organisasi $\left(\mathrm{X}_{2}\right)$. Koefisien korelasi budaya organisasi dengan Kepuasan kerja guru adalah $\mathrm{r}_{\mathrm{y} 1}=0,2728$ dan koefisien determinasi $\mathrm{r}_{\mathrm{y} 1}^{2}=0,4360$ yang dihasilkan, menunjukan tingkat hubungan yang sangat signifikan serta kontribusi yang diberikan oleh variable budaya organisasi adalah $27,28 \%$ sedangkan sisanya yaitu sebesar $72,72 \%$ dipengaruhi oleh faktor lain diluar variabel.

Berdasarkan secara teoritik dan didukung oleh penelitian yang relevan, terdiri atas hubungan antara budaya organisasi dengan Kepuasan kerja guru memiliki koefisien korelasi budaya organisasi sebesar $r_{\mathrm{y} 2}=0,2728$ dan penelitian yang relevan memiliki koefisien korelasi sebesar $\mathrm{r}=0.2728(\mathrm{P}<0.01)$. maka dapat disimpulkan bahwa hubungan antara budaya organisasi dengan Kepuasan kerja guru penelitian yang di teliti lebih besar dari penelitian yang relevan, maka dengan demikian penelitian ini tergolong sangat baik.

Berdasarkan Penelitian yang relevan oleh Angka Priatna dan Moehamad Ibnu Hasan "Hubungan Budaya Organisasi Dengan Kepuasan Kerja Studi Kasus Pada pt.Nipress, tbk." (2004: 9-10) memberikan kesimpulan bahwa terdapat hubungan positif yang signifikan ( $\mathrm{r}$ $=0,9521 \mathrm{p}<0,05)$ Hasil penelitian ini memberikan kesimpulan bahwa terdapat hubungan positif yang sangat signifikan antara budaya organisasi dengan Kepuasan kerja guru dengan koefisien korelasi sebesar $r=0.9521$ ( $\mathrm{P}<0.05$ ). berarti, semakin tinggi budaya organisasi, diprediksi akan semakin tinggi Kepuasan kerja guru.

\section{Hubungan antara Kepemimpinan Transformasional Kepala Madrasah $\left(X_{1}\right)$ dan Budaya Organisasi $\left(\mathbf{X}_{2}\right)$ dengan Kepuasan Kerja Guru (Y)}

Kuat lemahnya pengaruh antara variabel Kepemimpinan Transformasional Kepala Madrasah $\left(\mathrm{X}_{1}\right)$ dan Budaya Organisasi $\left(\mathrm{X}_{2}\right)$ secara bersama-sama dengan Kepuasan Kerja Guru (Y) dapat diketahui melalui analisi regresi ganda. Berdasarkan hasil analisasi data diperoleh persamaan regresi $\hat{\mathrm{Y}}=38+0,5660 \mathrm{X}_{1}+0,2728 \mathrm{X}_{2}$. Persamaan ini memberikan arti nilai variabel dependen Kepuasan kerja guru (Y) dipengaruhi oleh variabel independen Kepemimpinan Transformasional kepala madrasah $\left(\mathrm{X}_{1}\right)$ dan Budaya Organisasi $\left(\mathrm{X}_{2}\right)$.

Nilai koefisien korelasi ganda antara Kepemimpinan Transformasional kepala madrasah dan Budaya Organisasi dengan Kepuasan kerja guru adalah $r_{\mathrm{y} 1.2}=0,4921$. Hubungan ini cukup tinggi, yang berarti bahwa apabila Kepemimpinan Transformasional kepala madrasah dan Budaya Organisasi secara bersama-sama meningkat, maka Kepuasan kerja guru juga meningkat. Sedangkan koefisien determinasinya $r_{\mathrm{y} 1.2}^{2}=0,2422$, menunjukan tingkat hubungan yang signifikan. Kontribusi yang diberikan variabel Kepemimpinan Transformasional kepala madrasah dan Budaya Organisasi secara bersama-sama dengan Kepuasan kerja guru dalah $24,22 \%$ sedangkan sisanya yaitu sebesar $75,78 \%$ dipengaruhi oleh faktor lain diluar variabel yang diteliti.

Hasil perhitungan diperoleh $f_{\text {hitung }}>f_{\text {tabel }}$ maka Ho ditolak dan Ha diterima.Hal ini berarti bahwa terdapat hubungan yang positif dan signifikan antara Kepemimpinan Transformasional kepala madrasah dan budaya organisasi secara bersama-sama dalam meningkatkan Kepuasan kerja guru di Madrasah.

\section{SIMPULAN}

Berdasarkan analisis terhadap data hasil penelitian dapat disimpulkan terdapat hubungan positif sangat signifikan antara kepemimpinan transformasional kepala sekolah dengan kepuasan kerja guru, antara budaya organisasi dengan kepuasan kerja guru, antara 
kepemimpinan transformasional kepala sekolah dan budaya organisasi secara bersama-sama dengan kepuasan kerja guru. Berdasarkan hasil penelitian ini maka untuk meningkatkan kepuasan kerja guru dapat dilakukan dengan meningkatkan kepemimpinan transformasional kepala sekolah dan perbaikan pada budaya organisasi.

\section{DAFTAR PUSTAKA}

Edy Sutrisno. 2010, Budaya Organisasi. Jakarta: Kencana Prenada Media Group.

Schein, Edgar H. 2004, Organizational Culture \& Leadership. San Francisco: Jossey Bass.

Luthans, Fred. 2011, Organizational Behavior, An Evidence-Based Approach, Twelfth Edition.New York:McGraw-Hill Irwin.

Yukl, Gary. 2010. Leadership in Organization, Seventh Edition. New York. Person Education.Inc.

Hani Handoko. 2001, Manusia Manajemen Personalia dan Sumber daya Manusia, Yogyakarta: BPEE.

Hidayat, Rais. 2017. Perbaikan Komitmen Organisasional Guru Dalam Perspektif Kepemimpinan Kepala Sekolah Dan Kepuasan Kerja. Pedagogia 9(1): 490-96.

Husaini Usman, 2009, Manajemen Teori, Praktik, dan Riset Pendidikan, Jakarta: PT. Bumi Aksara.

Ismail Nawawi Uha, 2013, Budaya Organisasi Kepemimpinan dan Kinerja.proses terbentuk,tumbuh kembang, dinamika, dan kinerja organisasi. Jakarta: Prenadamedia Group.

Konopaske, Ivancevich., Matteson. 2008 Organizations Behavior and Management,Eight Edition.The Mc Graw Hill Companies.inc.

Gibson, James L., John M. Ivancevich, Donnelly, James H.Jr, dan Konopaske, Robert. 2012. Organizations Behavior-Structure-Processes, Fourteenth Edition,New York : Mc Graw Hill Companies.inc.

Colquit, Jason A., Lepine, Jefery A., Wesson , Michael J.2009. Organizational Behavior: Improving Performance And Commitment In The Work Place.Boston. McGraw-Hill Companies, Inc.

Malayu S.P. Hasibuan 2011, Manajemen Sumber daya Manusia, Jakarta: Bumi Aksara.

Marihot Tua Effendi Hariandja. 2009, Sumber daya Manusia, Jakarta: Grasindo.

Miftah Thoha. 2009, Perilaku Organisasi konsep dasar dan aplikasinya. Jakarta: Raja Grafindo Persada.

Schermerhorn, 2010. Management, Eight Edition USA: John Wiley and Sons.

Soekarso, Agus Sosro, Iskandar Putong dan Cecep Hidayat, 2010, Teori Kepemimpinan. Jakarta: Mitra wacana Media.

Robbins, Stephen P., Judge, Timothy A. 2013. Organizational Behavior. Fifteenth Edition.Boston: Person Education.Inc.

Sudarmanto. 2009. Kinerja dan pengembangan Kompetensi SDM. Yogyakarta: Pustaka Pelajar. Terjemahan Erlangga.Jakarta. 
Patras, Yuyun Elizabeth. 2017. Hubungan Kepuasan Kerja dan Iklim Organisasi dengan Komitmen Organisasional Guru. Pedagogia 9(1): 454. 